\title{
An Unusual Cause of Abnormal Cardiotocography
}

\author{
Vicente Rey y Formoso ${ }^{1} \cdot$ Aida Fernandez ${ }^{2} \cdot$ Manuela Rodrigues $^{3} \cdot$ Angelina Martins $^{3} \cdot$ Herćlíia Guimarães $^{3}$. \\ Ana Vilan ${ }^{3}$
}

Received: 13 October 2019 / Accepted: 26 February 2020 / Published online: 23 March 2020

(C) Dr. K C Chaudhuri Foundation 2020

To the Editor: Sinusoidal cardiotocograph (CTG) patterns are characteristic to fetal anemia (FA) [1-3]. One of the rare, but potentially life-threatening causes of FA is feto-maternal hemorrhage (FMH) [1-3]. We present a case of FMH whose FA was first suspected through inspection of the mother's CTG. This early suspicion prompted immediate, potentially lifesaving interventions.

A previously healthy, $33 \mathrm{wk}$ gravida, with an uneventful pregnancy to date, was admitted to our hospital complaining of reduced fetal movements (RFM) in the previous $5 \mathrm{~d}$. Close inspection of the CTG by the attending neonatologist revealed a sinusoidal pattern and FA was suspected. Transition to extrauterine life was planned accordingly, O Rh-ve blood was urgently requested, and an emergency $\mathrm{C}$-section was performed.

An extremely pale $[2.6 \mathrm{~g} / \mathrm{dl}$ hemoglobin concentration (HC)], hypotonic, bradycardic, $2400 \mathrm{~g}$ girl was delivered. No spontaneous respiratory movements were detectable. After intubation, one bolus of saline solution and $50 \mathrm{ml}$ of $\mathrm{O}$ Rh-ve blood were infused. At $1.5 \mathrm{~h}$ of life, $\mathrm{HC}$ was $11.8 \mathrm{~g} / \mathrm{dl}$ and vital signs were stable under mechanical ventilation. Early transfontanellar ultrasonography revealed diffuse brain edema. She was extubated on day 3 and, after a second blood transfusion, HC increased to $17.0 \mathrm{~g} / \mathrm{dl}$.

Since the blood types of both infant and mother were A $\mathrm{Rh}+\mathrm{ve}$ and maternal Parvovirus serologies were negative, a

Vicente Rey y Formoso

vicente-rey@hotmail.com

1 Department of Pediatrics, Maternal and Pediatrics Center, São João University and Hospital Center, Porto, Portugal

2 Department of Pediatrics, León University Hospital, León, Spain

3 Department of Neonatology, Maternal and Pediatrics Center, São João University and Hospital Center, Porto, Portugal
Kleihauer-Betke test was requested. The test's positive result confirmed FMH as the cause of FA.

An electroencephalogram on the 13th day revealed lower amplitude on the left hemisphere and found no ictal discharges, while a brain MRI detected diffuse white matter ischemic changes. The premature newborn was discharged on day 28 with a completely normal neurological examination.

CTGs are, now-a-days, widely available worldwide. When an antenatal patient complains of RFM, a CTG should be performed and monitored regularly - if sinusoidal patterns are detected, FA should be suspected. Particularly when more prevalent causes, such as maternal alloimmunization and parvovirus infection, have been excluded or are unlikely, FMH should be included in the differential diagnosis of FA. FMH can be tested for by Kleihauer-Betke method or flowcytometry [1-3]. Early diagnosis of FA (and FMH) and its appropriate management can facilitate transition to extrauterine life and perinatal care, preventing morbidity and mortality $[1,3]$.

\section{Compliance with Ethical Standards}

Conflict of Interest None.

\section{References}

1. Piva I, Iannone P, Morano D, Greco P. Untimely diagnosis of fetomaternal hemorrhage: what went wrong? J Perinat Med. 2018;47:61-7.

2. Prefumo F, Fichera A, Fratelli N, Sartori E. Fetal anemia: diagnosis and management. Best Pract Res Clin Obstet Gynaecol. 2019;58:214.

3. Stefanovic V. Fetomaternal hemorrhage complicated pregnancy: risks, identification, and management. Curr Opin Obstet Gynecol. 2016;28:86-94.

Publisher's Note Springer Nature remains neutral with regard to jurisdictional claims in published maps and institutional affiliations. 